\title{
Characteristics of cloud-to-ground lightning activity over Seoul, South Korea in relation to an urban effect
}

\author{
S. K. Kar ${ }^{1}$, Y.-A. Liou ${ }^{1}$, and K.-J. Ha ${ }^{2}$ \\ ${ }^{1}$ Center for Space and Remote Sensing Research, National Central University, Chung-Li, Taiwan \\ ${ }^{2}$ Div. of Earth Environmental System, College of Natural Science, Pusan National University, Busan 609-735, South Korea
}

Received: 2 March 2007 - Revised: 11 September 2007 - Accepted: 2 October 2007 - Published: 6 November 2007

\begin{abstract}
Cloud-to-ground (CG) lightning flash data collected by the lightning detection network installed at the Korean Meteorological Administration (KMA) have been used to study the urban effect on lightning activity over and around Seoul, the largest metropolitan city of South Korea, for the period of 1989-1999. Negative and positive flash density and the percentage of positive flashes have been calculated. Calculation reveals that an enhancement of approximately $60 \%$ and $42 \%$ are observed, respectively, for negative and positive flash density over and downwind of the city. The percentage decrease of positive flashes occurs over and downwind of Seoul and the amount of decrease is nearly $20 \%$ compared to upwind values. The results are in good agreement with those obtained by Steiger et al. (2002) and Westcott (1995). CG lightning activities have also been considered in relation to annual averages of $\mathrm{PM}_{10}$ (particulate matter with an aerodynamic diameter smaller than $10 \mu \mathrm{m}$ ) and sulphur dioxide $\left(\mathrm{SO}_{2}\right)$ concentrations. Interesting results are found, indicating that the higher concentration of $\mathrm{SO}_{2}$ contributes to the enhancement of CG lightning flashes. On the other hand, the contribution from $\mathrm{PM}_{10}$ concentration has not appeared in this study to be as significant as $\mathrm{SO}_{2}$ in the enhancement of CG lightning flashes. Correlation coefficients of 0.33 and 0.64 are found between the change in CG lightning flashes and the $\mathrm{PM}_{10}$ and $\mathrm{SO}_{2}$, respectively, for upwind to downwind areas, suggesting a significant influence of the increased concentration of $\mathrm{SO}_{2}$ on the enhancement of $\mathrm{CG}$ flashes.
\end{abstract}

Keywords. Meteorology and atmospheric dynamics (Convective processes; Lightning; Tropical meteorology)

\footnotetext{
Correspondence to: Y.-A. Liou

(yueian@csrsr.ncu.edu.tw)
}

\section{Introduction}

The urban effect on enhancing cloud-to-ground (CG) lightning activity over and downwind of cities has first been documented by Westcott (1995). Several studies have been performed after Westcott (1995) to study the effect of an urban area on the initiation and enhancement of CG lightning (e.g. Orville et al., 2001; Steiger et al., 2002; Soriano and Pablo, 2002). Most of these studies have ascribed the effect to the urban heat island circulation, along with a possible role for air pollution. The effects of an urban area on the local weather activities have been found in several studies (e.g. Changnon et al., 1981; Landsberg, 1981; Balling and Idso, 1989). A long-term study conducted by Steiger et al. (2002) on the percentage of positive flashes and peak current over Houston, Texas was the first to investigate the urban effect on lightning characteristics in these categories. They have reported a $-12 \%$ decrease in the percentage of positive flashes and no significant effect on the peak current of negative and positive CG flashes.

Due to the existence of a physical relationship between lightning activity and convective precipitation (Petersen and Rutledge, 1998; Soriano et al., 2001; Kar and Ha, 2003), urban effects on lightning are expected. However, the concentration of cloud condensation nuclei $(\mathrm{CCN})$ can be uplifted by the pollution over the cities, which, in turn, might produce changes in the microphysical processes taking place inside the clouds. As a result of such changes in cloud microphysical processes, a change in the charge separation processes in thunderclouds is expected because of its dependence on concentration, phase and the size of cloud particles. In the boundary layer the increased pollution is expected to be operative in suppressing the mean droplet size, and more cloud water would therefore be operative in separating the electric charge, leading to the creation of more CG lightning flashes (Orville et al., 2001). The urban enhancement of CG lightning activity that might be associated with high $\mathrm{PM}_{10}$

Published by Copernicus Publications on behalf of the European Geosciences Union. 
and $\mathrm{SO}_{2}$ concentrations has first been suggested by Westcott (1995). After that a long-term analysis over the city of Houston has been carried out by Orville et al. (2001) and they reported an association between urban heat island and anthropogenic pollution in the enhancement of flash density over and downwind of the urban area.

However, no attempt has yet been made to investigate the urban effect on lightning activity over the South Korean peninsula, except a few studies on lightning and precipitation (Kar and Ha, 2003; Lim and Lee, 2002). In this paper, a 10-year climatological analysis of lightning data was made over and near Seoul $\left(37^{\circ} 34^{\prime}, 126^{\circ} 58^{\prime}\right)$, which is one of the most populated cities in the world and is the capital of South Korea, with over ten million people. The urban area of Seoul is nearly $605 \mathrm{~km}^{2}$, and is similar to Houston in that both are situated near a coastal area. Flash density of both polarity and the percentage of positive flashes have been calculated. The results are presented and compared to those obtained by Steiger et al. (2002). Investigations have also been made on the possible influence of $\mathrm{PM}_{10}$ and $\mathrm{SO}_{2}$ on lightning activity and have been compared with the results available in the literature. As far as our knowledge is concerned, this is the first long-term study of the urban effect on lightning activity over a large city on the Korean peninsula.

\subsection{Data and methodology}

The lightning data used in this study have been collected from a lightning detection network installed by the Korean Meteorological Administration (KMA). The network consists of an advanced Position Analyzer, Model 280 (APA), Advanced Display System (ADS), Network Display System (NDS), Integrated Storm Information System (ISIS) and Advanced Lightning Direction Finder (ALDF, model 141), made by Lightning Location and Protection, Inc., which is currently known as Vaisala, Tucson, Arizona. Cloud-toGround (CG) lightning strikes are detected by each magnetic direction finder and the direction finder determines the direction toward a detected electromagnetic lightning discharge. Each lightning event, after being detected by the sensors, is transmitted to the position analyzer, to determine its polarity, amplitude, latitude, longitude, date and time of occurrence. Nearly $80 \%-90 \%$ of all CG lightning is automatically detected by a direction finder, which occurs within a nominal detectable distance of $400 \mathrm{~km}$, with less than 4-km accuracy. However, especially near the edges of the network, the assumption of $80 \%$ uniform flash detection efficiency may not be realistic. In our present analysis no attempt has been taken to correct the detection efficiency. The details of the detection efficiency of the lightning network from its past to its present form has been summarized by Cummins et al. (1998a, b) of Vaisala, Inc.

For this study, we have used a spatial scale of approximately $0.08^{\circ}$ latitude $\times 0.08^{\circ}$ longitude. The number of CG flashes within the specified block surrounding Seoul city has been counted. The area associated with each grid box is $\sim 8.8 \mathrm{~km} \times 6.6 \mathrm{~km} \sim 58 \mathrm{~km}^{2}$. Hence, each block associated with upwind, over and downwind comprises 10 grid boxes. These 10 grid boxes cover almost the whole urban area of Seoul. Generally, the upwind and downwind areas were selected based on the strong prevailing wind motion. The prevailing wind motion in the Korean peninsula has a clear southwesterly component and, hence, upwind (downwind) areas are located to the southwest (northeast) (Sun and Lee, 2002). In calculating the upwind, urban and downwind CG lightning flash density, we have followed the procedure adopted by Soriano (2002), but the selection of our spatial scale in counting the lightning flash is considerably different from that used by Soriano (2002), who used a spatial scale of $0.1^{\circ}$ latitude $\times 0.1^{\circ}$ longitude. Hence, to accomplish this, the number of CG flashes in blocks, each comprising 10 grid boxes, within the urban area of Seoul city, is counted. But in the case of upwind and downwind areas, first the number of CG flashes is counted in blocks which are located to the west, south-west, south, north, northeast and east of the town. Then the total number of CG flashes over upwind and downwind areas is counted by taking the mean of the three southwest and northeast blocks, respectively. The number of flashes within the urban area is then compared to that of the flashes in the upwind and downwind areas. Calculation of negative flash density, positive flash density and the percentage of positive flashes for upwind and downwind areas, have been made in a similar way. The number of grid boxes in upwind and downwind areas, for computing the number of lightning flashes, is equal to the number of grid boxes within urban area of Seoul city in which urban lightning flashes are counted. The number of grid boxes in upwind, urban downwind areas is equal. The number of lightning flashes in each block is counted for a ten-year period and then averaged. In calculating the total number of CG flashes over upwind, urban and downwind areas, we have ignored the polarity of lightning flash. In contrast, in calculating the flash densities of both polarities and the percentage of positive flashes, we have paid special attention to the polarity of lightning flashes. The percentage increase in the lightning flash density over a particular region has been calculated by taking the difference in the average flash density between that particular region and its neighbouring region and dividing it by the average flash density of the neighbouring region and finally multiplying the number by one hundred. Figure 1 shows the location of the sensors and Seoul city. The sensors automatically detect over $90 \%$ of all cloud-to-ground lightning occurring within a nominal detectable distance, with less than $1 \mathrm{~km}$ accuracy, as shown in Fig. 1. The system accuracy and detection efficiency are indicated by the thick black and gray contours, respectively. 


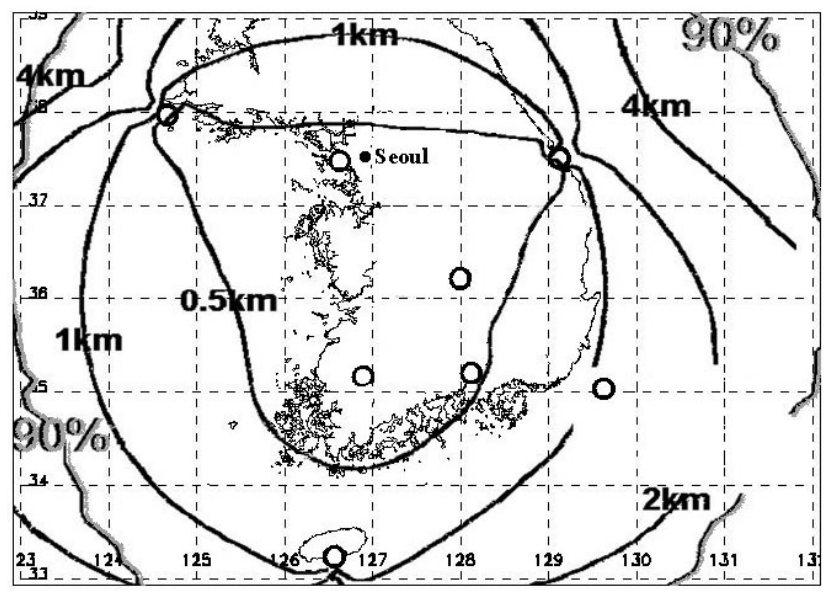

Fig. 1. Location of the sensors and the city of Seoul. Thick black and gray lines are system accuracy and detection efficiency, respectively. Small circles (o) indicate the location of lightning stations.

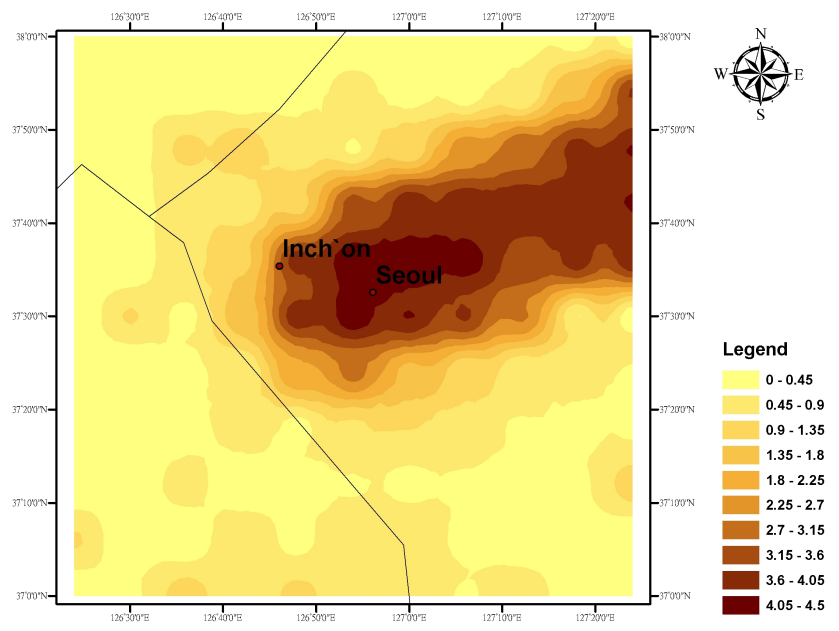

Fig. 2. Spatial distribution of negative flash density $\left(\mathrm{fl} \mathrm{km}^{-2} \mathrm{yr}^{-1}\right)$ over Seoul for the years 1989-1999.

\subsection{Results and discussion}

The spatial distribution of the mean annual negative and positive flash density over Seoul and nearby areas has been presented in Figs. 2 and 3, respectively. A significant enhancement of negative and positive flash density is noticed over and downwind of the city. The prevailing winds over the Korean peninsula have a clear southwesterly component and, hence, upwind (downwind) areas are located to the southwest (northeast). A significant enhancement of approximately $60 \%$ and $42 \%$ are observed, respectively, for negative and positive flash density over and downwind of the city, compared to the nearby surrounding areas. The percentage increase in the flash density found in this study corresponds well with the results reported by Wescott (1995) and Steiger et al. (2002), but it is bit low compared with the results found by Pinto et al. (2004).

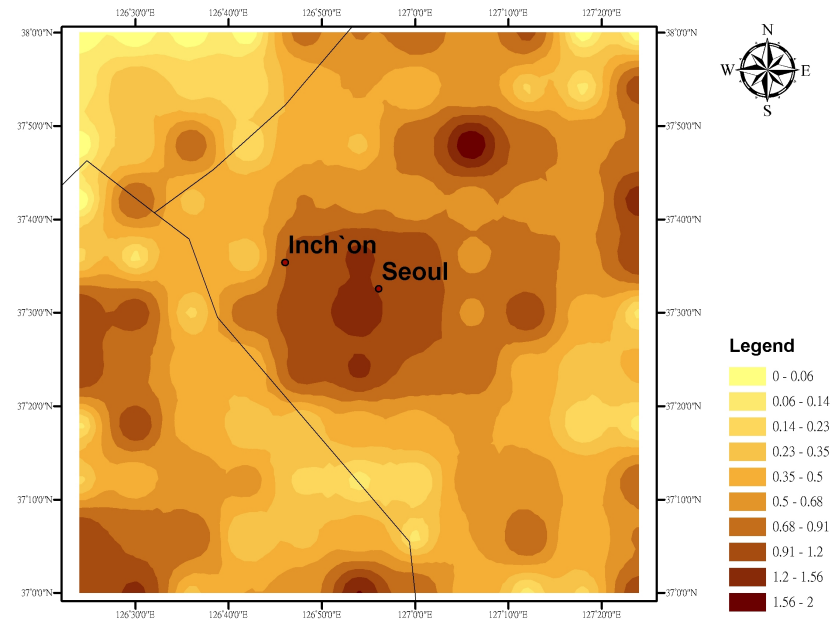

Fig. 3. Spatial distribution of positive flash density ( $\mathrm{fl} \mathrm{km}^{-2} \mathrm{yr}^{-1}$ ) over Seoul for the years 1989-1999.

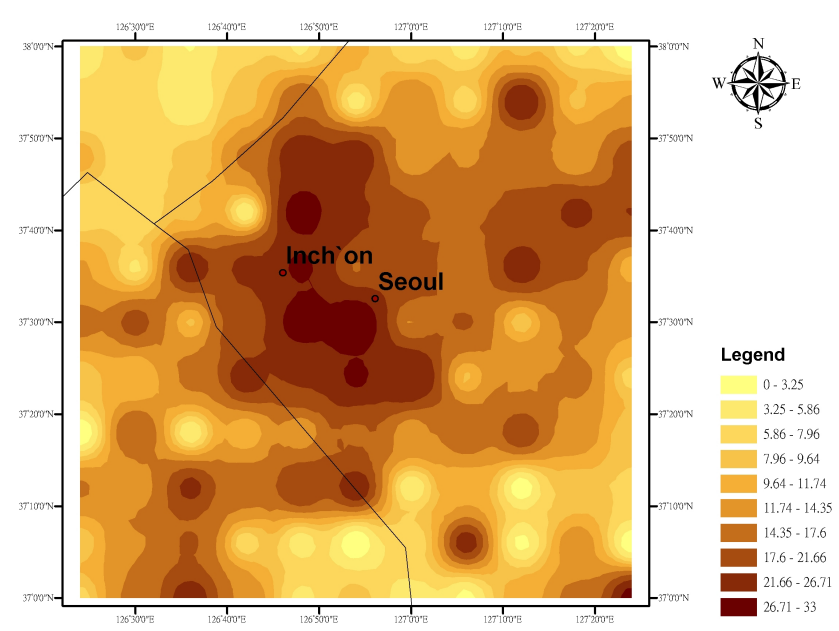

Fig. 4. Spatial distribution of percent positive flashes over Seoul for the years 1989-1999.

The spatial distribution of the percentage of positive flashes over Seoul and nearby areas has been depicted in Fig. 4. An approximate decrease in the percentage of positive flashes occurs over and downwind of Seoul. The percentage decrease of nearly $20 \%$ is evident compared to the surrounding areas. This result agrees fairly well with that obtained by Steiger et al. (2002), who reported a decrease of $-12 \%$ over Houston compared with surrounding areas. Possible explanations of such a decrease in percentage of positive flashes can be given from the microphysical processes of charge separation. The sign and magnitude of the charge transfer to the graupel target during ice crystal interaction is largely dependent on the impurities in the cloud water, as suggested by Jayaratne et al. (1983). During their experiment they have found that the graupel target charged negatively for all temperatures $\left(-6^{\circ} \mathrm{C}\right.$ to $\left.-25^{\circ} \mathrm{C}\right)$ after impurities 


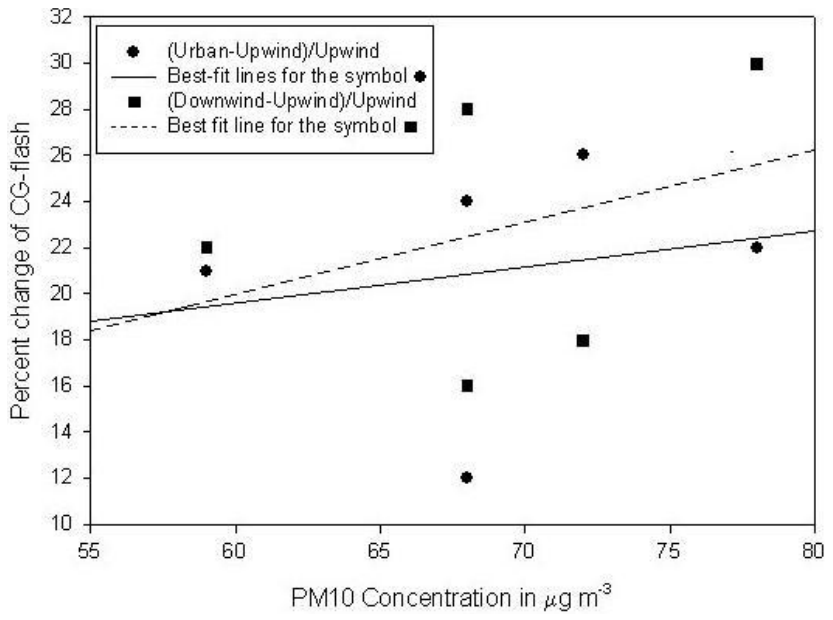

Fig. 5. Scatter plot and best-fit line of percent change in the number of $\mathrm{CG}$ flashes and annual averages of $\mathrm{PM}_{10}$ concentrations for the years 1995-1999.

were placed in the cloud. If the droplets contained a small amount of the most commonly available natural contaminants, the charge reversal temperature of $-25^{\circ} \mathrm{C}$ was shifted to higher temperatures. It is worth mentioning here that the charge reversal temperature is defined as the cloud temperature at which the charge transferred to the graupel pellet during ice crystal rebounding collision events changes sign. At low temperatures it is negative; at higher temperatures it is positive. Occurrence of such negative graupel charging due to increased impurities in the cloud water at higher temperatures can stretch the region of main negative charge lower to the cloud, covering the positive charge center below (Pruppacher and Klett, 1997, Fig. 18-2). The newly stretched region of negative charge of the thunderstorm tripolar charge distribution model (MacGorman and Rust, 1998) may generate more negative CG flashes, decreasing the relative frequency of positive flashes. It is worth mentioning in this context the results of Avila et al. (1999). They have found that for smaller-droplet spectrum the target graupel is charged positively over most of the temperature range they studied $\left(-10^{\circ} \mathrm{C}\right.$ to $\left.-25^{\circ} \mathrm{C}\right)$. But for larger droplet spectrum the target graupel is charged negatively at temperatures below $-18^{\circ} \mathrm{C}$ during ice-ice collisions in the presence of supercooled water. This suggests in the lower region of a thunderstorm containing a smaller droplet spectrum, the existence of a deeper positive charge center. This speculation of a deeper positive charge center intensifies further the possibility of higher percent positive values over an area favorable for the formation of such a type of droplet spectrum or over a polluted airmass. These above two hypotheses conflict with each other. Hence, an extensive analysis is required to resolve this ambiguity.

It has been found in several studies that the pollution can enhance convection in the downwind. For example, clouds downwind of particulate sources produce more rain than

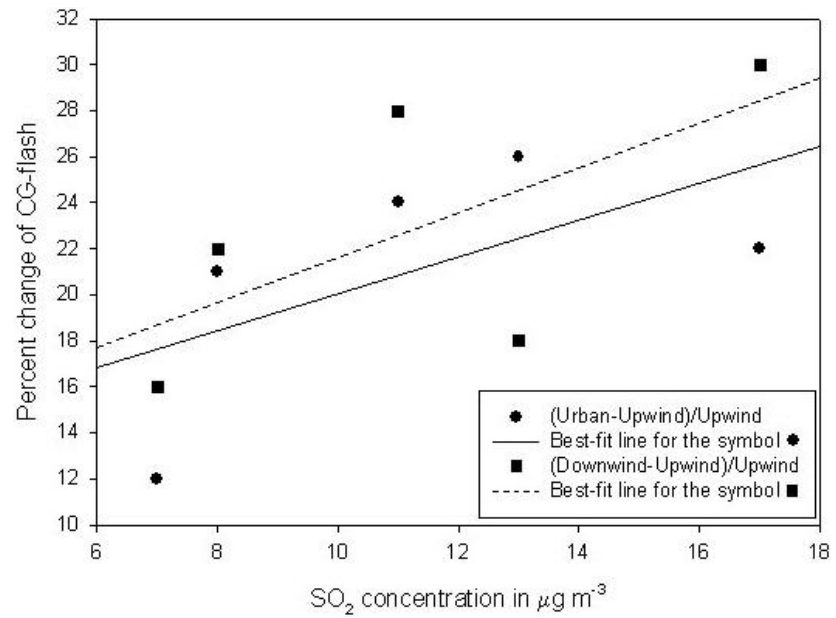

Fig. 6. Scatter plot and best-fit line of percent change in the number of $\mathrm{CG}$ flashes and annual averages of $\mathrm{SO}_{2}$ concentrations for the years 1995-1999.

other storms, as has been reported by Mather (1991). To study the effect of urban particulate matter on CG lightning activity, the annual averages of $\mathrm{PM}_{10}$ and $\mathrm{SO}_{2}$ concentrations have been considered in relation to the percent change in CG flashes. For the sake of simplicity we can treat these concentrations as gross indicators of the $\mathrm{CCN}$ concentrations. These data are available only from 1995 to 1999 . Hence, we have restricted our lightning data analysis for five years to maintain a consistency among the data sets. Figure 5 shows the scatter plot of $\mathrm{CG}$ lightning change with $\mathrm{PM}_{10}$ concentrations while Fig. 6 exhibits the same for CG lightning change with $\mathrm{SO}_{2}$ concentrations. Figure 6 suggests a connection between the percent change in CG flashes from upwind to the urban area and from upwind to the downwind area with $\mathrm{SO}_{2}$. On the other hand, in Fig. 5, the connection between $\mathrm{PM}_{10}$ concentrations and the percent change in CG flashes from upwind to the urban area and from upwind to the downwind area is not so conclusive as compared to $\mathrm{SO}_{2}$ concentrations. Hence, it may be concluded that increased concentration of $\mathrm{SO}_{2}$ contributes in enhancing the $\mathrm{CG}$ flashes but the increased $\mathrm{PM}_{10}$ concentration does not seem to be as influential a parameter as $\mathrm{SO}_{2}$ to the increase in lightning flashes. However, it has been suggested by Orville et al. (2001) that the production of CG lightning is enhanced by the increase in the mixed phase region cloud water and is paralleled by an increase in the separation of the electrical charge. Since the sulphate particles are usually more active in the formation of cloud droplets compared to $\mathrm{PM}_{10}$ (Seinfeld, 1975), a significant contribution from $\mathrm{SO}_{2}$ concentration is expected to the enhancement of CG lightning compared with $\mathrm{PM}_{10}$ concentration. Our results partially correspond to the report of Westcott (1995), but corroborate well the results of Soriano et al. (2002). Westcott (1995) has found that large annual values of $\mathrm{SO}_{2}$ and $\mathrm{PM}_{10}$ correspond generally to the large 
values of urban and downwind CG flash. Hence, data from other geographical locations and for more years are required to resolve this diversity in findings. Correlation coefficients between $\mathrm{PM}_{10}$ concentrations and the change in the number of CG flashes from upwind to urban and from upwind to downwind areas are found to be 0.30 and 0.33 , respectively, while the correlation coefficients between $\mathrm{SO}_{2}$ concentrations and the change in the number of CG flashes from upwind to urban and from upwind to downwind areas are found to be 0.55 and 0.64 , respectively. All the correlation coefficients are significant at the 99.9 confidence level and have been shown separately in Table 1 .

The effect of pollution on lightning production can be explained by the Rosenfeld hypothesis (Rosenfeld and Lensky, 1998; Williams et al., 1999). Rosenfeld and Lensky (1998) have shown by analyzing the data from the Advanced Very High Resolution Radiometer (AVHRR) that compared to rural clouds there is either a very narrow or no coalescence zone, with a deep mixed-phase zone and glaciation occurring at higher levels for the clouds forming over polluted regions. We have considered in our present analysis the annual number of lightning flashes and the annual average concentrations of $\mathrm{PM}_{10}$ and $\mathrm{SO}_{2}$. The higher $\mathrm{CCN}$ concentration over Seoul results in the reduction of mean cloud droplet size, which, in turn, decreases the process of coalescence and the droplet collision efficiency (Roger and Yau, 1989). Hence, it can be concluded that more supercooled water can exist at greater depths in clouds generated in a polluted atmosphere. Saunders (1993) has reported the dependence of the noninductive charge separation process on the amount of supercooled liquid water in the thundercloud. Abundance of supercooled water may generate large graupel, which, in turn, may produce enhanced storm electrification through collisions with ice particles. Enhancement of cloud buoyancy is also possible through the freezing process by the excess cloud water in the mixed phase zone.

\section{Conclusions}

An extensive long-term climatological study over Seoul, the capital city of South Korea, has been done for the years 1989-1999 using the lightning data from KMA. Results indicate a significant increase of nearly $60 \%$ and $42 \%$ in the negative and positive flash density, respectively, over and downwind of Seoul compared to the nearby surrounding areas. This study also reveals that a considerable $20 \%$ decrease in the percentage of positive flashes occurs over and the downwind of the city compared with upwind area. The results are in good agreement with those obtained by Steiger et al. (2002). $\mathrm{PM}_{10}$ and $\mathrm{SO}_{2}$ concentrations have been analyzed in relation to the $\mathrm{CG}$ lightning activities, considering the $\mathrm{PM}_{10}$ and $\mathrm{SO}_{2}$ concentrations as a gross indicator of CCN. Results indicate a contributory link between higher concentration of $\mathrm{SO}_{2}$ and the percentage change in the num-
Table 1. Correlation coefficients between percent change of CG flashes and $\mathrm{PM}_{10}$ and $\mathrm{SO} 2$ concentrations.

\begin{tabular}{lll}
\hline & $\mathrm{PM}_{10}$ & $\mathrm{SO}_{2}$ \\
\hline (Urban-Upwind)/Upwind & 0.30 & 0.55 \\
(Downwind-Upwind)/Upwind & 0.33 & 0.64 \\
\hline
\end{tabular}

ber of $\mathrm{CG}$ flashes. On the other hand, $\mathrm{PM}_{10}$ concentration was not as influential a factor in the enhancement of CG lightning flashes. Correlation coefficients of 0.33 and 0.64 are found, respectively, for $\mathrm{PM}_{10}$ and $\mathrm{SO}_{2}$ concentrations when compared separately with the percent change of CG lightning activity for upwind to downwind areas. However, for the upwind to urban area, correlation coefficients of 0.30 and 0.55 are found for $\mathrm{PM}_{10}$ and $\mathrm{SO}_{2}$, respectively, when compared with the percent change of CG lightning activity separately. Higher correlation coefficients between CG lightning activity and $\mathrm{SO}_{2}$ suggest a significant influence of the increased concentration of $\mathrm{SO}_{2}$ to the increase in $\mathrm{CG}$ flashes, which corroborates with the results of Soriano et al. (2002). This higher correlation coefficient strongly supports that the pollution plays a key role in the enhancement of lightning activity, as also suggested by Steiger and Orville (2003). It was Williams et al. (1999) who first proposed the pollution hypothesis for lightning enhancement. They suggested that in the case of the continental and dirty boundary layer, the available liquid water in the storm updraft is distributed amongst an innumerable number of small droplets, thereby suppressing mean droplet size and thwarting the coalescence process. As a result, the cloud water reaches the mixed phase region, thereby participating in the generation of excess cloud buoyancy, in the formation of precipitation, and in the separation of electric charge, thereby increasing the lightning activity.

Acknowledgements. The authors are extremely grateful to the two anonymous reviewers of this paper for their valuable critical comments on certain points and helping us improve this paper. We are also thankful to J.-H. Lee and E.-S. Jung of the Korean Meteorological Administration for providing the lightning data, to the National Science Council (NSC) of Taiwan for a financial grant (NSC 952811-M-008-033), and to the Ministry of Education (MOE), Taiwan for a financial grant "Project of Promoting Academic Excellence and Developing World Class Research Centers".

Topical Editor F. D'Andrea thanks S. Steiger and another anonymous referee for their help in evaluating this paper.

\section{References}

Avila, E. E., Pereyra, R. G., Varela, G. G. A., and Caranti, G. M.: The effect of the cloud-droplet spectrum on electrical charge transfer during individual ice-ice collisions, Q. J. Roy. Meteor. Soc., 125, 1669-1679, 1999. 
Balling, R. C. and Idso, S. B.: Historical temperature trends in the US and the effect of urban population growth, J. Geophys. Res., 84, 3359-3363, 1989.

Changnon, S. A., Semonin, R. G., Auer, A. H., Braham Jr., R. R., and Hales, J. M.: METROMEX: a review and summary, Meteor. Monog., 18, Am. Meteor. Soc., 181 pp, 1981.

Cummins, K. L., Krider, E. P., and Malone, M. D.: The US National Lightning Detection Network and applications of cloudto-ground lightning data by electric power utilities, IEEE Trans. Electromag. Compat., 40, 465-480, 1998a.

Cummins, K. L., Murphy, M. J., Bardo, E. A., Hiscox, W. L., Pyle, R. B., and Pifer, A. E.: A combined TAO/MDF technology upgrade of the US National Lightning Detection Network, J. Geophys. Res., 103D, 9035-9044, 1998b.

Jayaratne, E. R., Saunders, C. P. R., and Hallett, J.: Laboratory studies of the charging of soft-hail during ice crystal interactions, Q. J. Roy. Meteor. Soc., 109, 609-630, 1983.

Kar, S. K. and Ha, K. J.: Characteristics differences of rainfall and cloud-to-ground lightning activity over South Korea during the summer monsoon season, Mon. Weather Rev., 131, 2312-2323, 2003.

Landsberg, H. E.: The Urban Climate, Int. Geophys. Ser., 28, Academic, San Diego, Calif., 1981.

Lim, E. and Lee, T. Y.: Effect of lightning assimilation on the prediction of precipitation system associated with a cold front, Proc. 39th Spring Korean Meteorological Society Conf., Daegu, Korea, Korean Meteorological Society, 234-238, 2002.

MacGorman, D. R. and Rust, W. D.: The electrical nature of storms, Oxford Univ. Press, New York, 1998.

Mather, G. K.: Coalescence enhancement in large multi-cell storms caused by emissions from a Kraft paper mill, J. Appl. Meteorol., 30, 1134-1146, 1991.

Orville, R. R., Huffines, G., Gammon, J. N., Zhang, R., Ely, B., Steiger, S., Phillips, S., Allen, S., and Read, W.: Enhancement of cloud-to-ground lightning over Houston, Texas, Geophys. Res. Lett., 28(13), 2597-2600, 2001.

Petersen, W. A. and Rutledge, S. A.: On the relationship between cloud-to-ground lightning and convective rainfall, J. Geophys. Res., 103, 14 025-14 040, 1998.

Pinto, I. R. C. A., Pinto Jr., O., Gomes, M. A. S. S., and Ferreira, N. J.: Urban effect on the characteristics of cloud-to-ground lightning over Belo Horizonte-Brazil, Ann. Geophys., 22, 697-700, 2004 ,

http://www.ann-geophys.net/22/697/2004/.
Pruppacher, H. R. and Klett, J. D.: Microphysics of clouds and precipitation, Atmos. Oceanogr. Sci. Libr., Kulwer Acad., Norwell, Mass., 1997.

Rogers, R. R. and Yau, M. K.: A Short Course in Cloud Physics, Int. Ser. Nat. Philos., Pergamon, Tarrytown, N.Y., 1989.

Rosenfeld, D. and Lensky, I. M.: Satellite-based insights into precipitation formation processes in continental and maritime convective clouds, B. Am. Meteorol. Soc., 79, 2457-2476, 1998.

Saunders, C. P. R.: A review of thunderstorm electrification processes, J. Appl. Meteorol., 32, 642-654, 1993.

Seinfeld, J. M.: Air Pollution: Physical and Chemical Fundamentals, McGraw-Hill Co., New York, 1975.

Soriano, L. R. and Pablo, F.: Effect of small urban areas in central Spain on the enhancement of cloud-to-ground lightning activity, Atmos. Environ., 36, 2809-2816, 2002.

Soriano, L. R., Pablo, F. D., and Diez, E. G.: Relationship between convective precipitation and cloud-to-ground lightning in the Iberian Peninsula, Mon. Weather Rev., 129, 2998-3003, 2001.

Steiger, S. M., Orville, R. E., and Huffines, G.: Cloud-to-ground lightning characteristics over Houston, Texas: 1989-2000, J. Geophys. Res., 107(D11), 4117, doi:10.1029/2001JD001142, 2002.

Steiger, S. M. and Orville, R. E.: Cloud-to-ground lightning enhancement over Southern Louisiana, Geophys. Res. Lett., 30(19), 1975, doi:10.1029/2003GL017923, 2003.

Sun, J. and Lee, T.-Y.: A numerical study of an intense quasistationary convection band over the Korean Peninsula, J. Meteor. Soc. Japan., 80, 1221-1245, 2002.

Westcott, N. E.: Summertime cloud-to-ground lightning activity around major Midwestern urban areas, J. Appl. Meteorol., 34, 1633-1642, 1995.

Williams, E., Rosenfeld, D., Madden, N., Labrada, C., Gerlach, J., and Atkinson, L.: The role of boundary layer aerosol in the vertical development of precipitation and electrification: Another look at the contrast between lightning over land and over ocean, Reprints, in Eleventh International Conference on Atmospheric Electricity, pp. 754-757, Am. Meteorol. Soc., Boston, Mass., 1999. 